\title{
Carbon nanotubes dispersed polymer nanocomposites: mechanical, electrical, thermal properties and surface morphology
}

\author{
NITIN SANKAR, MAMILLA NAGARJUN REDDY and R KRISHNA PRASAD* \\ Department of Chemical Engineering \& Materials Science, Center of Excellence in Advanced Materials \& Green \\ Technology, Amrita Vishwa Vidyapeetham University, Ettimadai, Coimbatore 641 112, India
}

MS received 2 July 2015; accepted 27 August 2015

\begin{abstract}
The various properties and surface morphology of the carbon nanotubes (CNTs) dispersed polydimethyl siloxane (PDMS) matrix were studied to determine their usefulness in various applications. The tensile strength, Young's modulus and electrical breakdown strength of CNT/polymer composites were 0.35 MPa, 1.2 MPa and $8.1 \mathrm{kV}$, respectively. The thermal conductivity and dielectric constant for the material having 4.28 wt $\%$ CNT were $0.225 \mathrm{~W} \mathrm{~m}^{-1} \mathrm{~K}^{-1}$ and 2.329, respectively. The CNT/polymer composites are promising functional composites with improved mechanical and electrical properties. The scanning electron microscope analysis of surface morphology of PDMS/CNT composite showed that the rough surface texture on nanocomposite has large surface area with circular pores. The Fourier transform infrared spectroscopy showed the functional groups present in polymer nanocomposite.
\end{abstract}

Keywords. Carbon nanotubes; nanocomposite; Young's modulus; breakdown strength; dielectric constant; thermal conductivity.

\section{Introduction}

The polymer composite has material characteristics useful for diverse applications such as capacitors and acoustic emission sensors. The nanoscaled fillers are dispersed in polymers to improve their conductivity [1]. The nanocomposite materials have polymer matrix reinforced by separate nanomaterial to improve their properties [2]. The polymers are filled with particles that improve their stiffness and toughness of material, enhance barrier properties, and improve their resistance to fire [3]. The polymers are mostly reinforced by fillers to increase their mechanical, optical, and electrical properties and also to introduce antibacterial properties to the material [4].

The nanosized particles are distributed in polymer to occupy large number of sites in the polymer matrix to improve their strength and other properties. The reinforcement with nanoparticle improves the properties such as modulus, heat resistance, electrical conductivity, and structural strength but reduces gas permeability and flammability $[5,6]$. The reinforcement with nanocomposite improves the UV shielding and UV resistance of transparent polymers [7]. The particle agglomerations of nanoparticles are avoided by incorporating them in polymer matrix [8]. The polymer nanocomposite has wide applications in the field of microwave absorbing, data storage, sensors, and biomedical applications [9].

The polydimethylsiloxane (PDMS) and multi-walled carbon nanotube (MWCNT) nanocomposite have elastomeric

\footnotetext{
*Author for correspondence (rkprasad_cbe@rediffmail.com)
}

nanocomposite feature in photosimulated mechanical response [10] and applied in fields such as electronic packaging material and angular acceleration accelerometers [11]. The PDMS is a silicon-based organic polymer composed of a repeating $\left[\mathrm{SiO}\left(\mathrm{CH}_{3}\right)_{2}\right]$ unit and is in rubber state at room temperature as its glass transition temperature is less than $-120^{\circ} \mathrm{C}$. It possesses hydrophobic, non-conductive, and biocompatible properties useful in various applications such as casting moulds and micro-fluidic devices and also useful in medical devices owing to properties such as oxygen permeability, optical transparency, and self-healing property [12]. Young's modulus of PDMS can be reduced by reducing the relative amount of curing agent to base material while mixing the polymer [13]. The PDMS exists as clear, colourless, viscous, and transparent liquid [14] and is a hyperelastic polymer that undergoes big distortions without deteriorations $[15,16]$.

The carbon nanotubes (CNTs) consist of graphene sheets rolled to form a tube which exist as multi-walled, doublewalled, and single-walled CNTs depending on layers of graphene sheets $[17,18]$. The electrical current carrying capacity of CNT is thousand times larger than a copper wire. CNT has high strength, toughness, large surface area, and hollow geometry $[19,20]$. CNTs are reinforcement materials adding multifunctionality to a composite system as they have excellent mechanical, electrical, and optical properties along with their ability to adhere to chemical species or functional groups [21-24]. The incorporation of CNT into polymer improves their tensile strength, toughness, glass transition temperature, thermal conductivity, electrical conductivity, and optical properties [25-27]. The PDMS/CNT nanocomposites 
are prepared by different techniques such as emulsion polymerization, electrospinning, melt blending, bulk polymerization, in-situ polymerization, intercalation of polymer from solution, dispersion destabilization and exfoliation [28]. The effect of surfactant and MWCNTs in a silicone matrix were studied by several researchers [29]. In this study dispersion of CNT on PDMS is achieved by solution mixing with chloroform as solvent.

\section{Materials and methods}

The PDMS procured from Dow Corning as Sylgard 184 elastomer kit consisting of elastomer and curing agent and the MWCNT procured from Nanoshel has diameter of 20-39 nm, length of $15-30 \mu \mathrm{m}$, and relative purity of $>95 \%$. The MWCNT is mixed with $200 \mathrm{ml}$ of chloroform in ultrasonicator for an hour and PDMS with $40 \mathrm{ml}$ of chloroform in a magnetic stirrer for $15 \mathrm{~min}$ and both these mixtures were mixed in ultrasonicator for $1-2 \mathrm{~h}$. The ultrasonicated mixture was kept in oven at $62^{\circ} \mathrm{C}$ for $4 \mathrm{~h}$ to evaporate the solvent. The base polymer to curing agent ratio added was $10: 1$ and the mixture was transferred to a tray to obtain correct shape, length, thickness, and kept in oven at $150^{\circ} \mathrm{C}$ to cure the nanocomposite.

The tensile strength and Young's modulus were determined by conducting tensile test using universal testing machine. The tensile strength was recorded directly and Young's modulus was calculated from the stress-strain curve obtained from the test. The breakdown strength was determined by conducting breakdown test using a transformer oil test set.

Table 1. The experimental range of factors studied in preparation of PDMS-CNT nanocomposite.

\begin{tabular}{lcc}
\hline Factors & Minimum value & Maximum value \\
\hline $\begin{array}{c}\text { Amount of MWCNT } \\
\text { (g/50 ml solvent) } X_{1}\end{array}$ & 0.2 & 0.3 \\
g of PDMS/ml of solvent $X_{2}$ & 0.5 & 0.7 \\
Time of sonication (h) $X_{3}$ & 1 & 2 \\
\hline
\end{tabular}

The experimental range of factors studied are amount of MWCNT $\left(X_{1}\right)$, amount of PDMS $\left(X_{2}\right)$ and time of sonication $\left(X_{3}\right)$ as given in table 1 . The factorial design model used to determine various responses like tensile strength $\left(Y_{1}\right)$, Young's modulus $\left(Y_{2}\right)$ and breakdown strength $\left(Y_{3}\right)$ is expressed as follows:

$$
\begin{aligned}
Y= & \beta_{0}+\beta_{1} X_{1}+\beta_{2} X_{2}+\beta_{3} X_{3}+\beta_{11} X_{1}^{2}+\beta_{22} X_{2}^{2} \\
& +\beta_{33} X_{3}^{2}+\beta_{12} X_{1} X_{2}+\beta_{13} X_{1} X_{3}+\beta_{23} X_{2} X_{3},
\end{aligned}
$$

where $Y$ is the predicted response; $\beta_{0}$ the model constant; $\beta_{1}, \beta_{2}$ and $\beta_{3}$ the linear coefficients; $\beta_{11}, \beta_{22}$ and $\beta_{33}$ the quadratic or square coefficients; $\beta_{12}, \beta_{13}$ and $\beta_{23}$ the cross product or interaction coefficients. $X_{1}, X_{2}$ and $X_{3}$ are various parameters studied. The Fourier transform infrared spectroscopy (FT-IR) was recorded using Thermo Nicolet is 10 FT-IR spectrometer using $\mathrm{KBr}$ pellets in the range of 500$4000 \mathrm{~cm}^{-1}$. The scanning electron microscope (SEM) analysis was carried out using SEM VEGA3 TESCAN instrument operated at acceleration voltage of 5 and $30 \mathrm{kV}$ to analyse the surface morphology of PDMS-MWCNT nanocomposite.

The thermal conductivity was determined by conducting experiment in Hot Disk PPS-2500S instrument. The storage and loss modulus were recorded using DMA6100 HITACHI instrument. The thermal stability was analysed by using TGA-6200 HITACHI instrument and the dielectric constant was determined by dielectric constant meter at $1 \mathrm{MHz}$ at $30^{\circ} \mathrm{C}$. The electrical conductivity was measured by electric conductometer instrument. The X-ray diffraction (XRD) was recorded using Pan analytica at $40 \mathrm{kV}$ and $30 \mathrm{~mA}$.

\section{Results and discussions}

\subsection{Process model and contour regions of tensile strength in polymeric nanocomposite}

The tensile strength, Young's modulus, and breakdown strength of PDMS/CNT composite for eight sets of nanocomposites prepared are given in table 2 . The regression correlation

Table 2. Tensile strength, Young's modulus and breakdown strength for design of experiments studied in preparation of PDMS-CNT nanocomposite.

\begin{tabular}{lccccc}
\hline $\begin{array}{l}\text { Amount of MWCNT } \\
(\mathrm{g} / 50 \mathrm{ml} \text { solvent })\end{array}$ & $\begin{array}{c}\mathrm{g} \text { of PDMS/ } \\
10 \mathrm{ml} \text { of solvent }\end{array}$ & $\begin{array}{c}\text { Time of } \\
\text { sonication }(\mathrm{h})\end{array}$ & $\begin{array}{c}\text { Tensile strength } \\
(\mathrm{MPa})\end{array}$ & $\begin{array}{c}\text { Young's modulus } \\
(\mathrm{MPa})\end{array}$ & $\begin{array}{c}\text { Breakdown strength } \\
(\mathrm{kV})\end{array}$ \\
\hline 0.2 & 7 & 2 & 0.0214 & 0.38 & 7.4 \\
0.2 & 7 & 1 & 0.1214 & 0.78 & 7 \\
0.2 & 5 & 1 & 0.1929 & 0.58 & 7.2 \\
0.3 & 7 & 2 & 0.0929 & 0.49 & 7.6 \\
0.3 & 5 & 1 & 0.3571 & 1.038 & 7.5 \\
0.3 & 7 & 1 & 0.2643 & 1.26 & 7.5 \\
0.2 & 5 & 2 & 0.1214 & 0.34 & 7.5 \\
0.3 & 5 & 2 & 0.1429 & 0.342 & \\
\hline
\end{tabular}


for tensile strength irrespective of significances is expressed as follows:

$$
\text { Tensile strength: } \begin{aligned}
Y_{1}= & -0.7049+5.384 X_{1} \\
& +0.071 X_{2}+0.6416 X_{3} \\
& -0.463 X_{1} X_{2}-3.2 X_{1} X_{3} \\
& -0.085 X_{2} X_{3}+0.3565 X_{1} X_{2} X_{3} .
\end{aligned}
$$

The maximum amount of tensile stress which a material can withstand before failure is known as its tensile strength. The tensile strength of a material provides the extent to which a material can be stretched. The contour plot of tensile strength as a function of change in amount of MWCNT and dispersion time is shown in figure 1 which provides maximum tensile strength of $0.3 \mathrm{MPa}$ in nanocomposite with $0.26-0.30 \mathrm{~g}$ MWCNT dispersion in PDMS for an hour of ultrasonication. The contour plot shown in figure 2 represents the operating regions of amount of MWCNT dispersed in PDMS having tensile strength of $0.3 \mathrm{MPa}$ for $0.3 \mathrm{~g}$ MWCNT dispersed in 5-6 g PDMS. The interactions of various factors on tensile strength are shown in figure 3 which provides that the tensile stress improved with the addition of MWCNT and reduced with the increase in amount of PDMS and dispersion time.

\subsection{Contour analysis and interactions of Young's modulus in PDMS/MWCNT nanocomposite}

The regression correlation for Young's modulus based on uncoded units irrespective of significances is expressed as follows:

$$
\begin{aligned}
& \text { Young's modulus: } Y_{2}=-2.228+10.74 X_{1} \\
& +0.244 X_{2}+1.502 X_{3} \\
& -0.32 X_{1} X_{2}-6.71 X_{1} X_{3} \\
& -0.166 X_{2} X_{3}+0.43 X_{1} X_{2} X_{3} \text {. }
\end{aligned}
$$

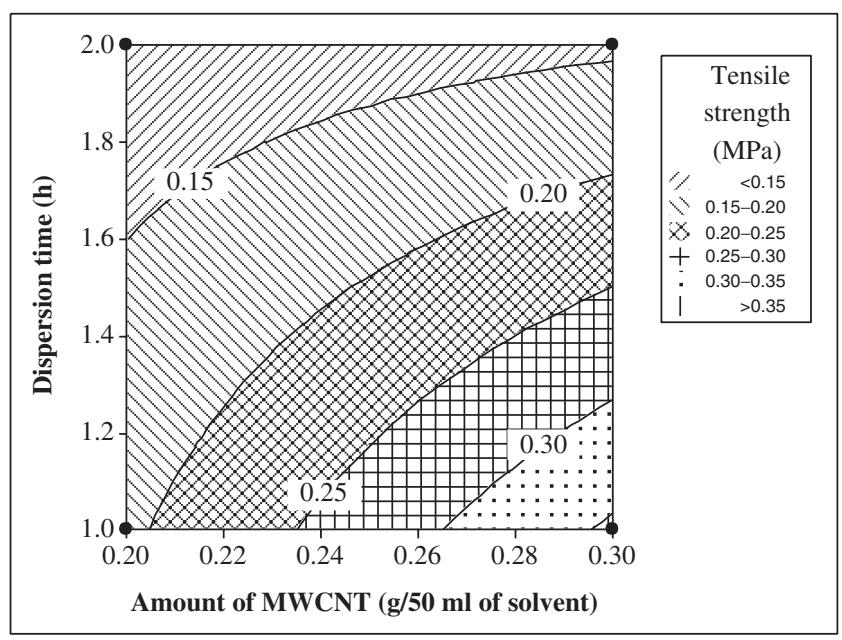

Figure 1. Contour plot of tensile strength $v s$. dispersion time and amount of MWCNT.
Young's modulus of material measures the material's elasticity. Figure 4 shows the operating regions of amount of MWCNT mixed with PDMS provides Young's modulus of 1.2 MPa for dispersion of MWCNT $(0.28-0.3 \mathrm{~g})$ in PDMS $(6.5-7 \mathrm{~g})$. The contour plot shown in figure 5 represents the amount of MWCNT and dispersion time provides Young's modulus of $0.9 \mathrm{MPa}$ for $0.27-0.3 \mathrm{~g}$ MWCNT dispersion in PDMS for an hour. Young's modulus of PDMS/CNT nanocomposites was improved with the increase in amount of MWCNT as observed from figure 6 which provides the interactions of various factors on Young's modulus.

3.2a Dynamic mechanical analysis: The dynamic mechanical properties of PDMS/CNT nanocomposite samples four and five are shown in figures 7 and 8 , respectively. The dynamic mechanical properties of PDMS/CNT nanocomposite are determined by dynamic storage and loss moduli. Storage modulus $\left(E^{\prime}\right)$ is the stress in phase in a sinusoidal deformation divided by strain. The loss modulus $\left(E^{\prime \prime}\right)$ is defined as the stress $90^{\circ}$ out of phase with the strain divided by the strain. It is a measure of energy lost as heat per cycle of sinusoidal deformation when different systems are compared at the same strain amplitude

$$
E^{*}=E^{\prime}+\mathrm{i} E^{\prime \prime} .
$$

\subsection{Contour regions and interactions of breakdown strength of polymeric nanocomposite}

The regression correlation for breakdown strength based on uncoded units irrespective of significances is expressed as follows:

$$
\text { Breakdown strength: } \begin{aligned}
Y_{3}= & 3.95+X_{1}+0.15 X_{2} \\
& +7.656 X_{3}+X_{1} X_{2} \\
& -20.5 X_{1} X_{3}-0.95 X_{2} X_{3} \\
& +2.5 X_{1} X_{2} X_{3} .
\end{aligned}
$$

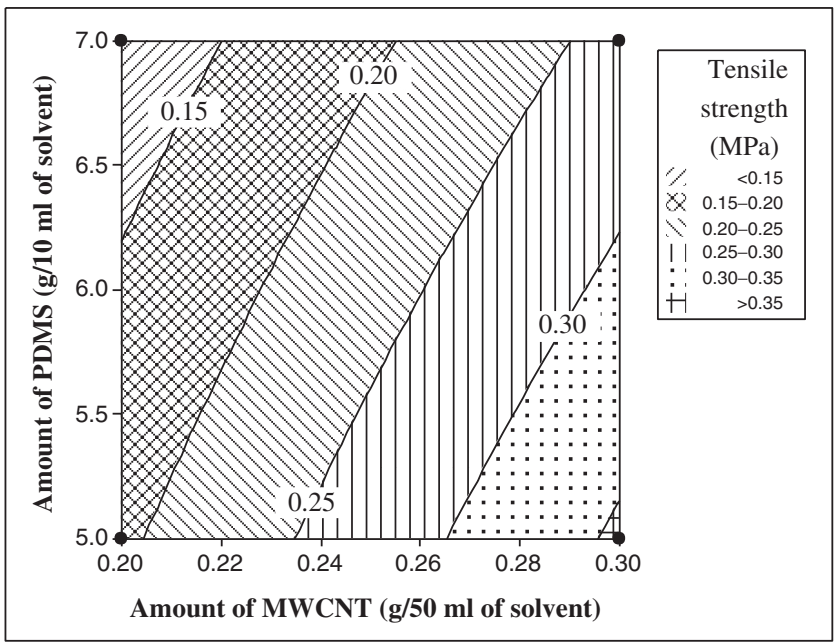

Figure 2. Contour plot of tensile strength vs. amount of PDMS and amount of MWCNT. 


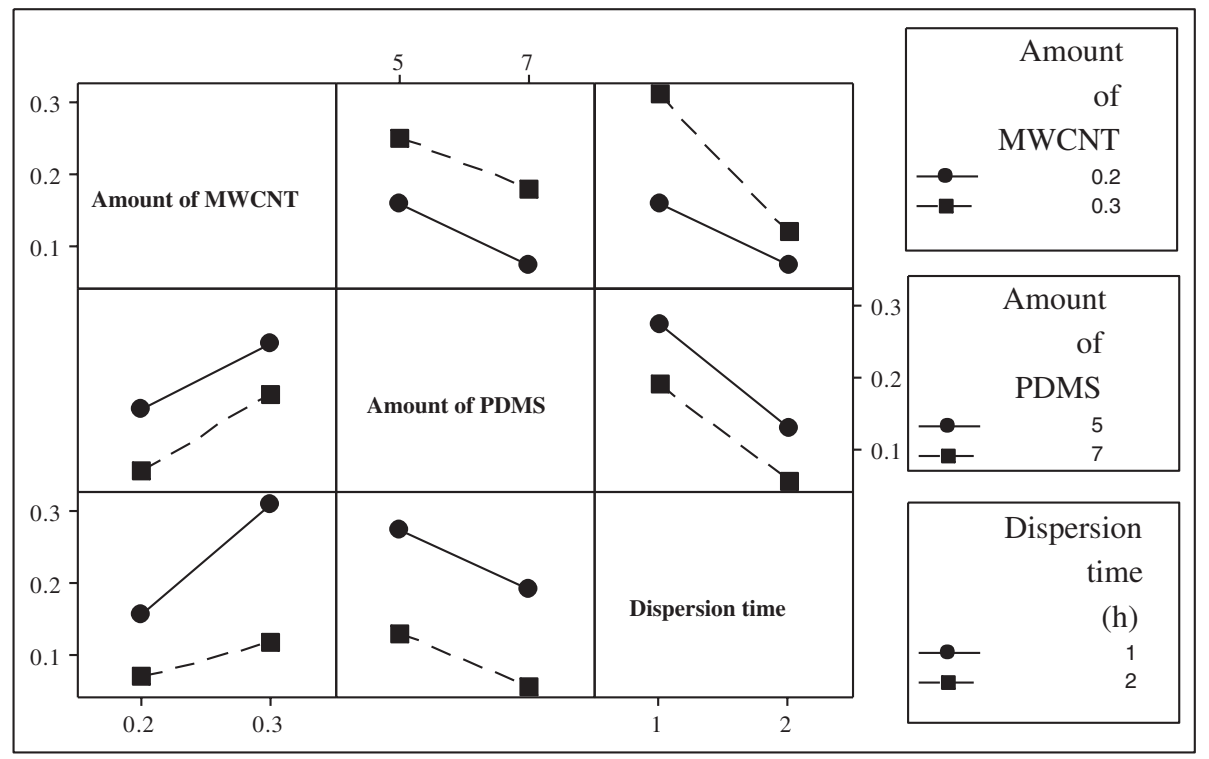

Figure 3. Interaction plot for tensile strength.

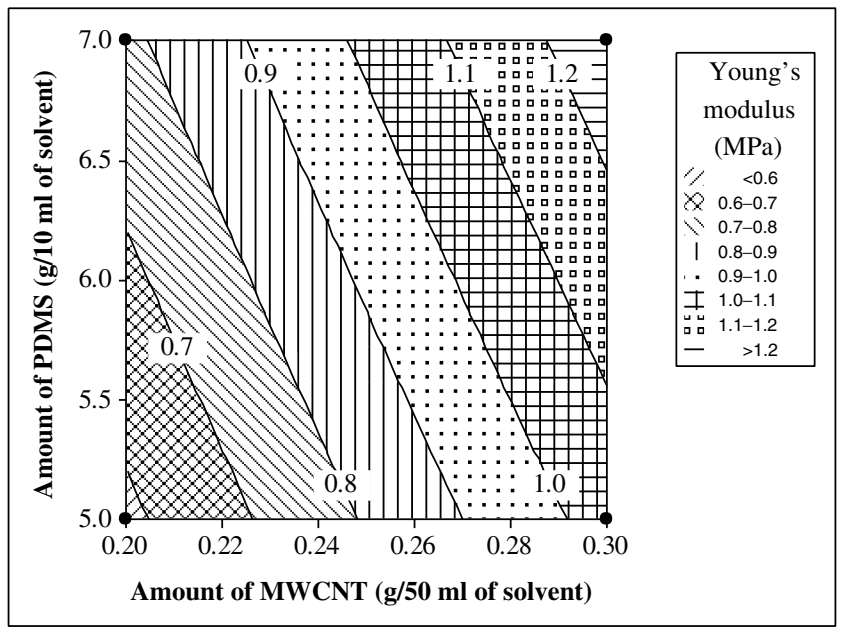

Figure 4. Contour plot of Young's modulus vs. amount of PDMS and amount of MWCNT.

The breakdown strength is the maximum electric field a material can withstand without breaking down. The contour region shown in figure 9 indicates maximum breakdown strength of $8.1 \mathrm{kV}$ for dispersion of $0.28-0.3 \mathrm{~g}$ MWCNT in $6.5-7 \mathrm{~g}$ PDMS matrix. The contour region of amount of MWCNT and dispersion time is shown in figure 10 provides maximum breakdown voltage of $8.1 \mathrm{kV}$ for $2 \mathrm{~h}$ ultrasonication of nanocomposite. It is observed from interaction matrix that breakdown strength shown in figure 11 has positive effect with the increase in amount of MWCNT and dispersion time.

\subsection{FT-IR of PDMS/CNT nanocomposite}

The FT-IR spectral analysis of PDMS/CNT nanocomposite for fifth set of design of experiments is shown in figure 12 .

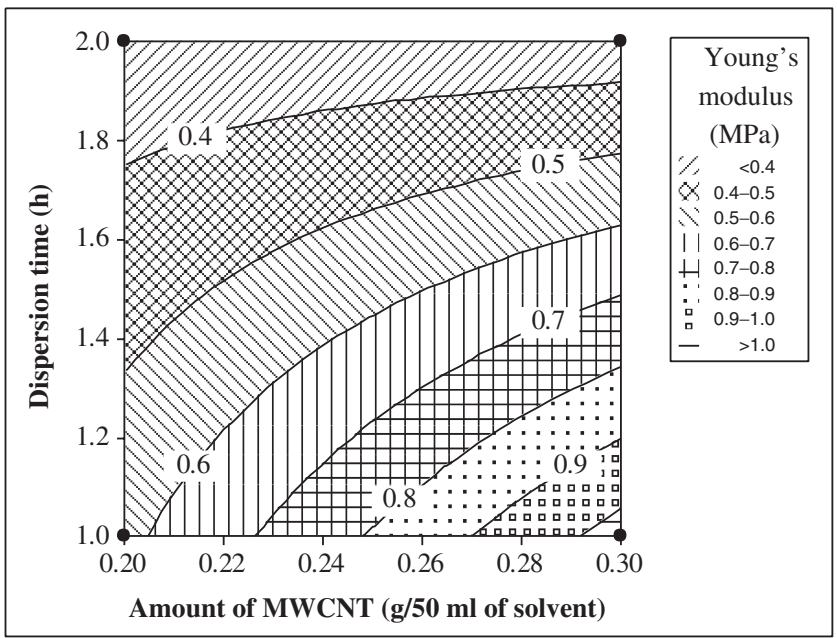

Figure 5. Contour plot of Young's modulus vs. dispersion time and amount of MWCNT.

The major peaks of synthesized nanocomposite belonged to $\mathrm{C}-\mathrm{H}$ and $\mathrm{O}-\mathrm{H}\left(2961 \mathrm{~cm}^{-1}\right), \mathrm{C}=\mathrm{C}$ and $\mathrm{CH}_{3}$ bending vibration $\left(1412 \mathrm{~cm}^{-1}\right), \mathrm{Si}-\mathrm{CH}_{2}-\mathrm{Si}$ and $\mathrm{C}-\mathrm{O}$ stretching $\left(1011 \mathrm{~cm}^{-1}\right)$, $\mathrm{Si}-\mathrm{CH}_{2}-\mathrm{CH}=\mathrm{CH}_{2}\left(910 \mathrm{~cm}^{-1}\right), \mathrm{C}-\mathrm{C}\left(842 \mathrm{~cm}^{-1}\right), \mathrm{CH}$ and $\mathrm{OH}$ bending vibrations $\left(687 \mathrm{~cm}^{-1}\right)$. The $\mathrm{Si}-\mathrm{CH}_{3}$ group is recognized by a sharp band at $1260 \mathrm{~cm}^{-1}$ and another strong band in the $865-750 \mathrm{~cm}^{-1}$ range. This indicates the presence of polysiloxane group present in polydimethylsiloxane. The peak at $2961 \mathrm{~cm}^{-1}$ is due to $-\mathrm{CH}_{2}$ and $-\mathrm{CH}_{3}$ stretching and the peak at $1011 \mathrm{~cm}^{-1}$ is attributed to $\mathrm{Si}-\mathrm{O}$ plane stretching.

\subsection{Estimation of properties of polymeric nanocomposites}

3.5a Thermal stability: The thermogravimetric analysis (TGA) for fourth and fifth set of PDMS/CNT nanocomposite 


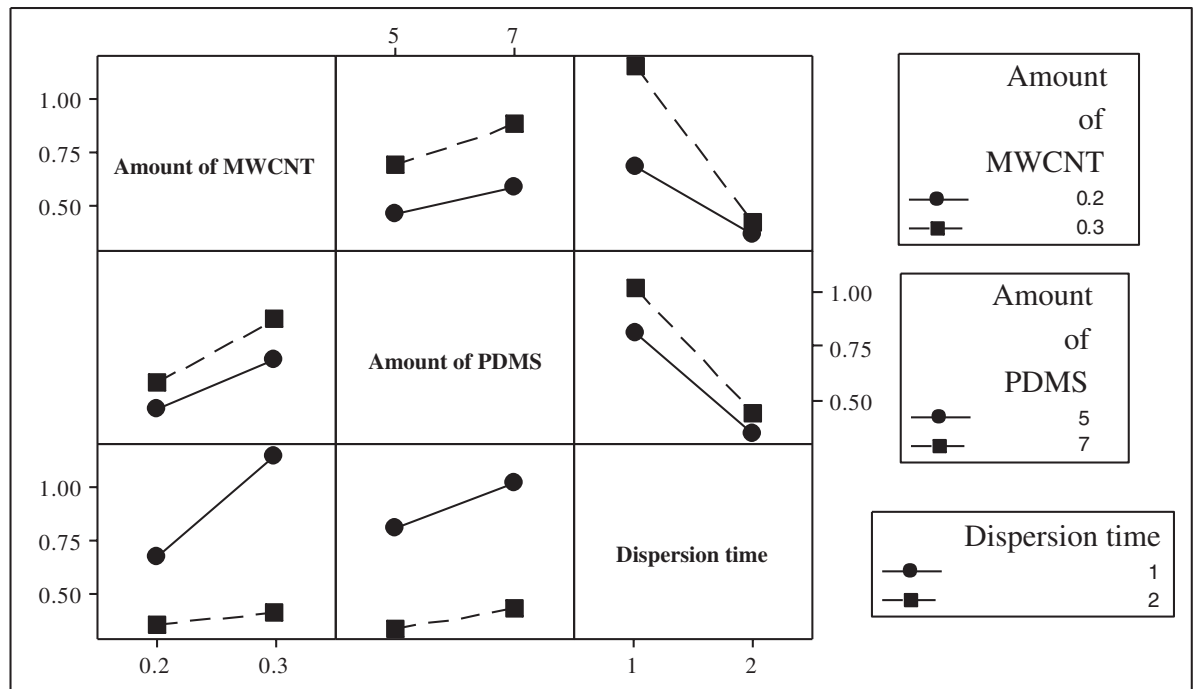

Figure 6. Interaction plot for Young's modulus.

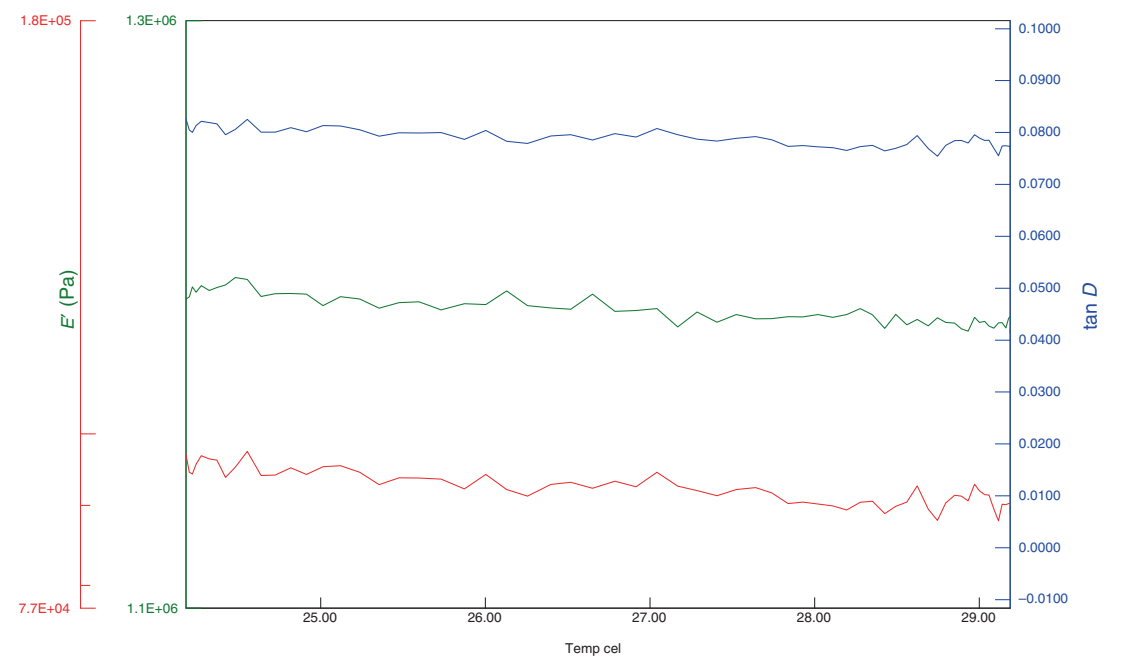

Figure 7. Dynamic mechanical properties for $0.3 \mathrm{~g}$ MWCNT dispersion (Sample 4).

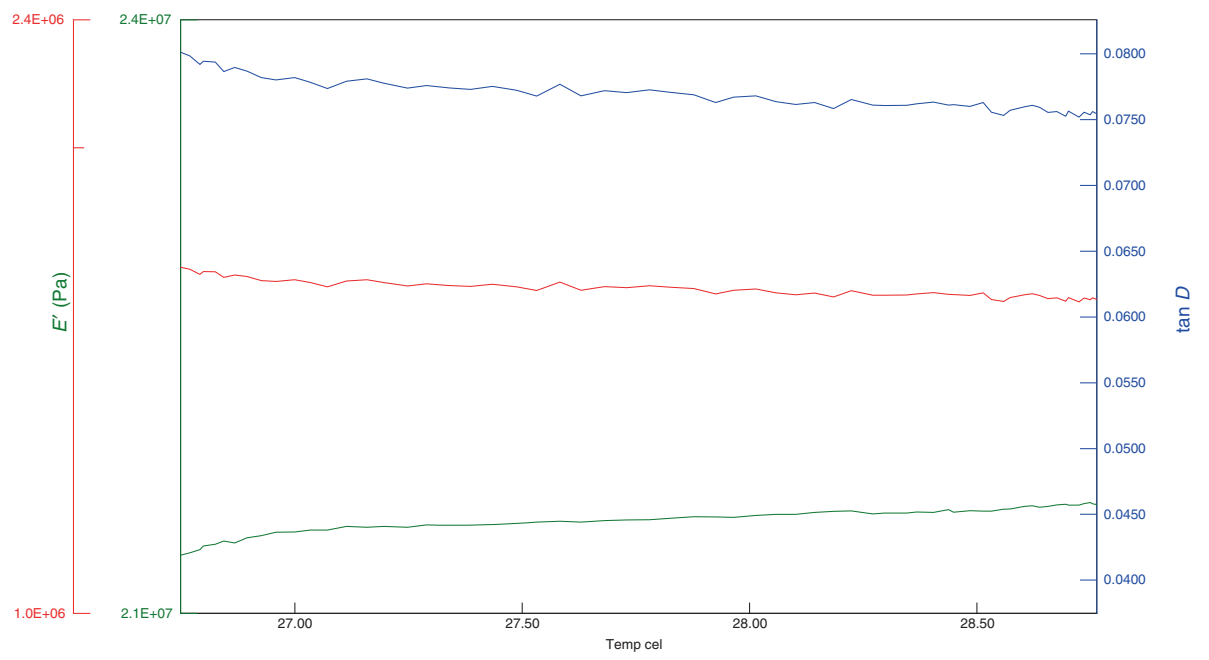

Figure 8. Dynamic mechanical properties for $0.3 \mathrm{~g}$ MWCNT dispersion (Sample 5). 


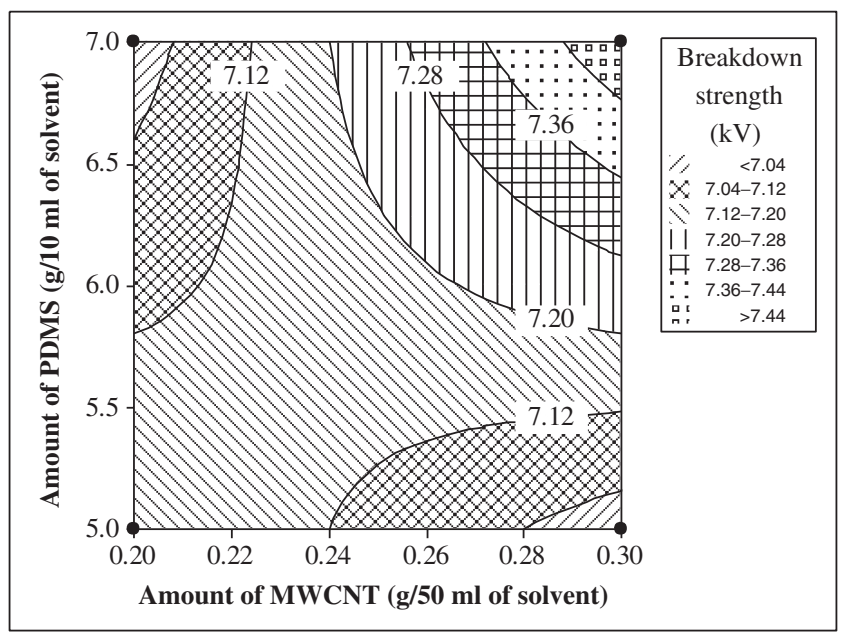

Figure 9. Contour plot of breakdown strength vs. amount of PDMS and amount of MWCNT.

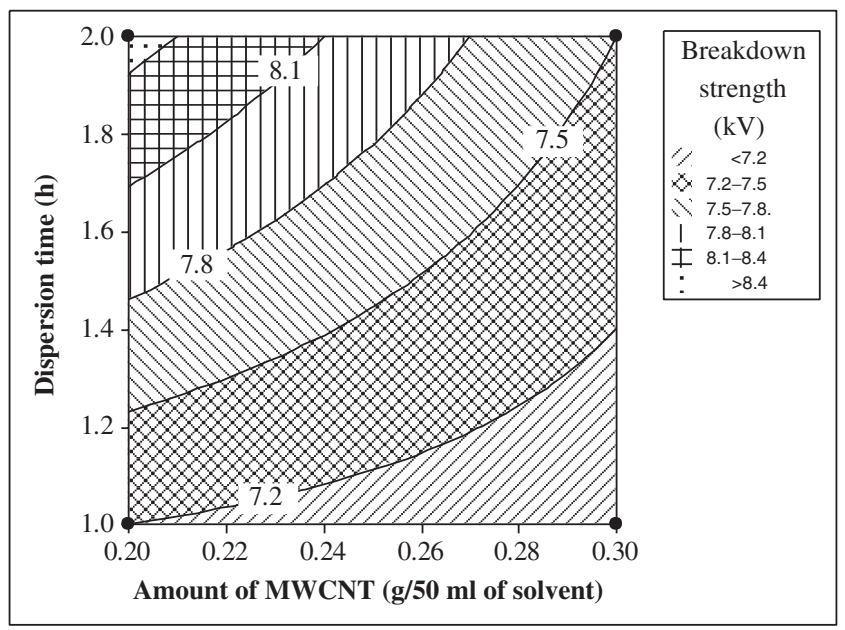

Figure 10. Contour plot of breakdown strength vs. dispersion time and amount of MWCNT. was performed. The thermal stability of a material is described as resistance to decomposition at high temperatures. The specimen with $4.28 \mathrm{wt} \%$ MWCNT has thermal stability of $273^{\circ} \mathrm{C}$ and the specimen with $6 \mathrm{wt} \%$ MWCNT has thermal stability of $322^{\circ} \mathrm{C}$. The thermal stability of PDMS/CNT nanocomposites improves with the increase in MWCNT. The presence of CNT within the PDMS matrix increases the thermal stability and electrical conductivity. The improvements in thermal stability are concurrent with the relative loading of CNT within PDMS matrix. Nanotubes have structural perfection, high electrical conductivity and chemical stability.

3.5b Thermal conductivity: The thermal conductivity of a material is described as the property to conduct heat. The thermal conductivity for fourth set of PDMS/CNT nanocomposite with $4.28 \%$ MWCNT is $0.225 \mathrm{~W} \mathrm{~m}^{-1} \mathrm{~K}^{-1}$.

3.5c Electrical conductivity: The electrical conductivity analysis for PDMS/CNT nanocomposite of fourth and fifth set is recorded. The electrical conductivity of a material is described as the degree to which a specified material can conduct electricity. The electrical conductivity of the specimen with $4.28 \mathrm{wt} \%$ MWCNT is $2.24 \times 10^{13} \Omega \mathrm{m}$ and for the specimen with $6 \mathrm{wt} \%$ MWCNT is $4.65 \times 10^{13} \Omega \mathrm{m}$. The electrical conductivity of PDMS/CNT improves with the increase in MWCNT.

3.5d Dielectric constant: The dielectric constant for PDMS/CNT nanocomposite of fourth and fifth set was measured. The dielectric constant of a material is a quantity measuring the ability to store electrical energy in an electrical field. The dielectric constant of specimen with $4.28 \mathrm{wt} \%$ MWCNT is 2.329 and for specimen with $6 \mathrm{wt} \%$ MWCNT is 11.753. The dielectric constant improves with the increase in MWCNT.

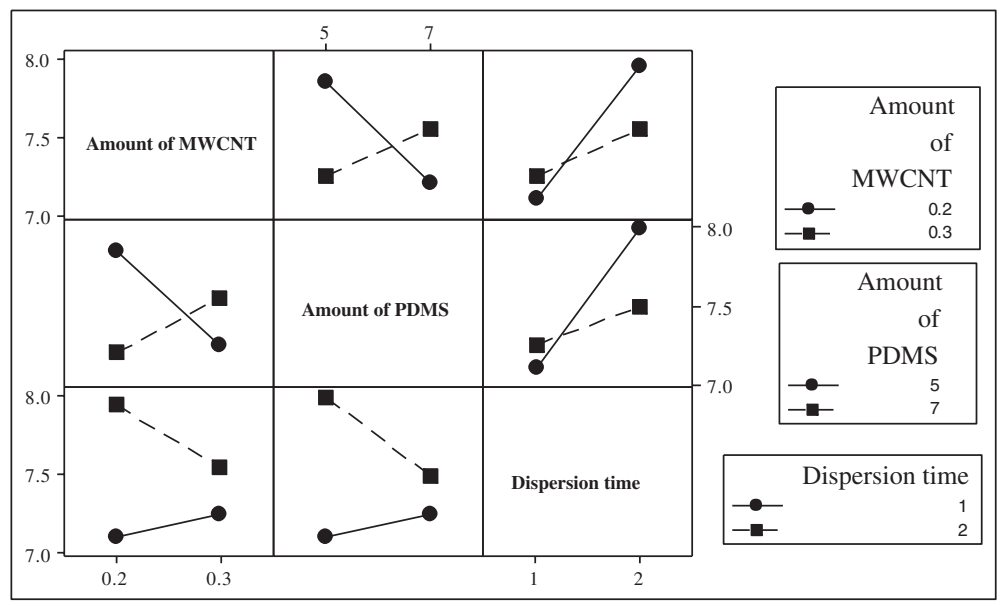

Figure 11. Interaction plot for breakdown strength. 


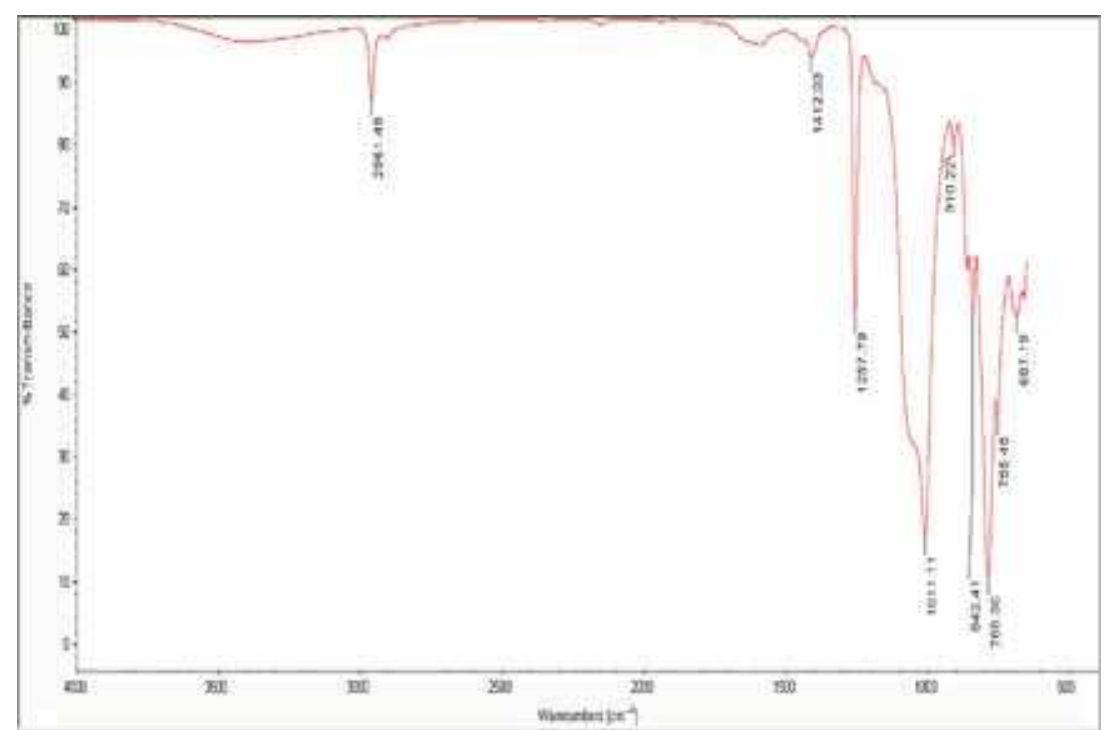

Figure 12. FT-IR spectral analysis of PDMS-CNT nanocomposite (Set 5: Amount of MWCNT $=0.3 \mathrm{~g} / 50 \mathrm{ml}$ solvent, amount of PDMS $=5 \mathrm{~g}$ of PDMS $/ 10 \mathrm{ml}$ of solvent, and time of sonication $=1 \mathrm{~h}$ ).
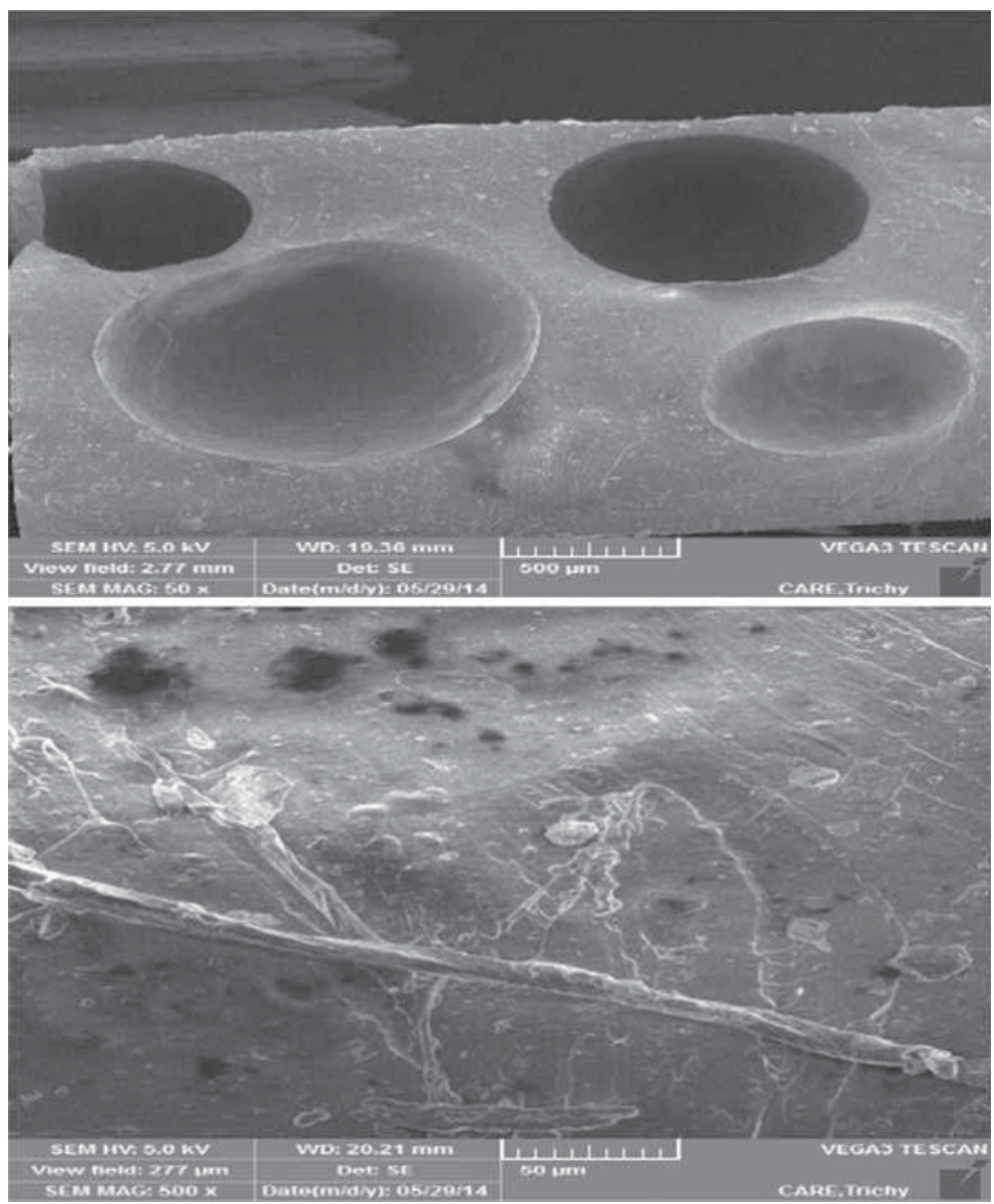

Figure 13. SEM images of PDMS-MWCNT nanocomposite (scale bar: 500 $\mu \mathrm{m}, 50 \mu \mathrm{m}$ ). (Set 5: Amount of MWCNT $=0.3 \mathrm{~g} / 50 \mathrm{ml}$ solvent, amount of $\mathrm{PDMS}=5 \mathrm{~g}$ of PDMS/10 $\mathrm{ml}$ of solvent, and time of sonication $=1 \mathrm{~h}$ ). 

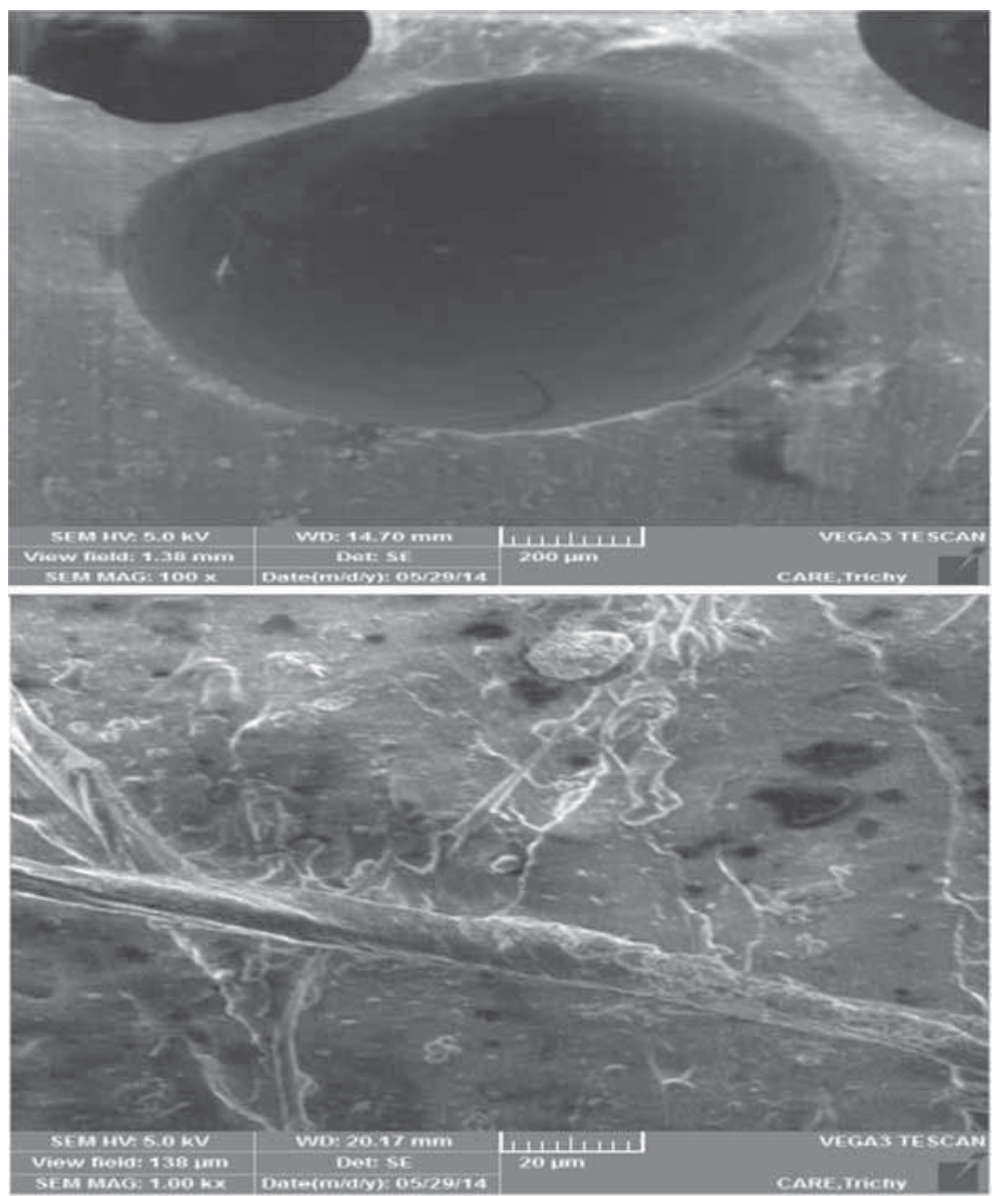

Figure 14. SEM images of PDMS-MWCNT nanocomposite (scale bar: 200 $\mu \mathrm{m}, 20 \mu \mathrm{m}$ ). (Set 5: Amount of MWCNT $=0.3 \mathrm{~g} / 50 \mathrm{ml}$ solvent, amount of $\mathrm{PDMS}=5 \mathrm{~g}$ of PDMS $/ 10 \mathrm{ml}$ of solvent, and time of sonication $=1 \mathrm{~h}$ ).

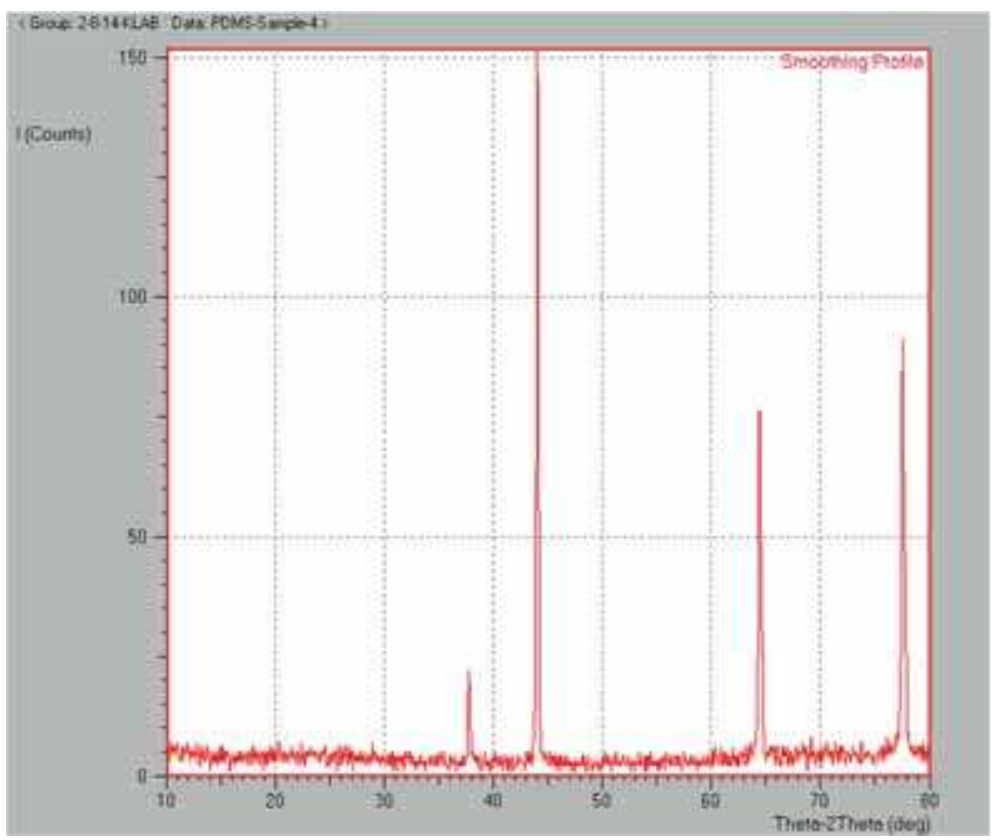

Figure 15. XRD spectra pattern of PDMS/CNT nanocomposite. 


\subsection{SEM studies of PDMS/CNT nanocomposite}

The SEM images of fifth set of PDMS/CNT nanocomposite at different resolution scale bar are shown in figures 13 and 14. The SEM imaging is useful to study the surface morphology and understand surface texture. The imaging was carried out at various degrees of magnification for better analysis. The surface porosity is visible in SEM images and is as shown in figure 13 for scale bar $50 \mu \mathrm{m}$. The $20 \mu \mathrm{m}$ SEM magnification shows tubular structure with crossing over as shown in figure 14. The SEM imaging at scale bar 200 and $500 \mu \mathrm{m}$ provides detailed pore structure and size and the pores are circular in shape as seen in the images. The good bonding strength between PDMS and CNT improved Young's modulus of PDMS. The rough surface texture on nanocomposite is observed from the SEM images that have large surface area and nano sized textures useful in selective adsorption applications. XRD has been employed to help qualify the degree of shape and orientation preference. The XRD patterns of PDMS/CNT nanocomposite are presented in figure 15. XRD is used to measure in polymer nanocomposites the efficiency of intercalation in the lamellar galleries. The peaks are broadened due to microstrain or grain size broadening.

\section{Conclusions}

The reinforcing of PDMS polymer with MWCNT provides significant improvement in its mechanical and electrical properties. The dispersion of $0.3 \mathrm{~g}$ MWCNT in polymer composite resulted in tensile stress and Young's modulus of 0.35 and 1.2 $\mathrm{MPa}$, respectively. The breakdown strength of PDMS/CNT composite improved with the increase in amount of MWCNT and dispersion time. The $\mathrm{Si}-\mathrm{CH}_{3}$ group is recognized by a sharp band at $1260 \mathrm{~cm}^{-1}$ in the polymer nanocomposite. The rough surface texture on nanocomposite was observed from the SEM images having large surface area and nanosized textures.

\section{References}

[1] Liu C-X and Choi J W 2012 Nanomaterials 2329

[2] Hu H, Onyebueke L and Abatan A 2010 J. Miner. Mater. Charact. Eng. 9275
[3] Alexandre M and Dubois P 2000 Mater. Sci. Eng. R 281

[4] Ahmed D S, Haider A J and Mohammed M R 2013 Energy Procedia 361111

[5] Huang Y Y and Terentjev E M 2012 Polymers 4275

[6] Giannelis E P 1998 Appl. Organomet. Chem. 12675

[7] Li Y-Q, Fu S-Y, Yang Y and Mai Y-W 2008 Chem. Mater. 20 2637

[8] Leite E R, Carreno N L V, Longo E and Pontes F M 2002 Chem. Mater. 143722

[9] Agarwal T, Gupta K, Zaidi M G H and Alam S 2012 Nanosci. Nanotechnol. 25

[10] Kim T and Kim H 2010 Korea Aust. Rheol. J. 22205

[11] Nayak S, Chaki T K and Khastgir D 2013 Adv. Mater. Res. 622897

[12] King M G, Bargawanath A J, Rosamond M C, Wood D and Gallant A J 2009 Procedia Chem. 1568

[13] Talaei S, Frey O, Van Der Waal P D, De Rooij N F and Koudelka M 2009 Procedia Chem. 1381

[14] Bourbaba H, Achaiba C B and Mohammed B 2013 Energy Procedia 36231

[15] Lotters J C, Olthuis W, Veltink P H and Bergveld P 1997 J. Micromech. Microeng. 7145

[16] Punbusayakul N 2012 Procedia Eng. 32683

[17] Huang J and Rodrigue D 2014 Mater. Des. 55653

[18] Meng N and Zhou N-L 2014 Carbohydr. Polym. 10570

[19] Fang J, Shan X-Q and Huang R-X 2013 Geoderma 2071

[20] Zhao D, Zhang W, Chen C and Wang X 2013 Procedia Environ. Sci. 18890

[21] Khatiwada S, Armada C A and Barrera E V 2013 Procedia Eng. $\mathbf{5 8} 4$

[22] Das R, Ali M E, Abd Hamid S B, Ramakrishna S and Cowdhary Z Z 2014 Desalination 33697

[23] Nguyen Q T and Baird D G 2006 Adv. Polym. Technol. 25270

[24] Li C and Shi G 2014 J. Photochem. Photobiol. 1920

[25] Huang Y Y and Terentjev E M 2012 Polymers 4275

[26] Sahoo N G, Rana S, Cho J W, Li L and Chan S H 2010 Prog. Polym. Sci. 35837

[27] Erdem Yalcinkaya S, Yildiz N, Sacak M and Calimli A 2010 Turk. J. Chem. 34581

[28] Morales-Games L, Jones I, Franco L and Puiggali J 2011 Express Polym. Lett. 8717

[29] Vilčáková J, Moučka R, Svoboda P, Ilčíková M, Kazantseva N, Hřibová M, Mičušík M and Omastová M 2012 Molecules 1713157 